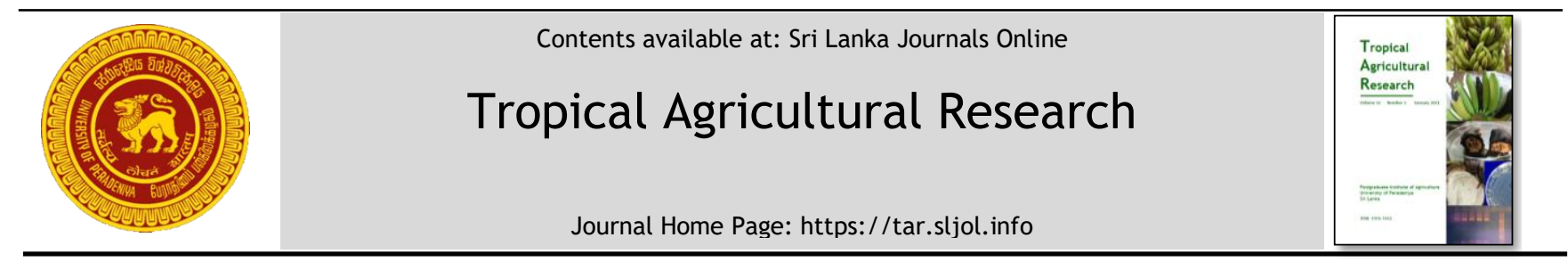

\title{
Returns to Factors of Production and Total Factor Productivity in Coconut Plantations in Sri Lanka
}

\author{
M.G.D. Abeysekara ${ }^{1 *}$ and D.V.P. Prasada ${ }^{2}$ \\ ${ }^{1}$ Postgraduate Institute of Agriculture, University of Peradeniya, Peradeniya, Sri Lanka. \\ ${ }^{2}$ Department of Agricultural Economics and Business Management, Faculty of Agriculture, University of Peradeniya, \\ Peradeniya, Sri Lanka.
}

\section{ARTICLE INFO}

\section{Article history:}

Received: 15 July 2020

Revised version received: 14 October 2020

Accepted: 05 November 2020

Available online: 1 January 2021

\section{Keywords:}

Coconut

Growth decomposition

Scale of economies

Technological change

Total factor productivity

\section{Citation:}

Abeysekara, M.G.D. and Prasada, D.V.P. (2021). Returns to Factors of Production and Total Factor Productivity in Coconut Plantations in Sri Lanka. Tropical Agricultural Research, 32(1): 58-67.

DOI: http://doi.org/10.4038/tar.v32i1.8442

Abeysekara, M.G.D.

https://orcid.org/0000-0002-1777-565X

\section{ABSTRACT}

The objective of this study was to identify the sources of productivity growth of the Sri Lankan coconut sector by decomposing the measured growth in total factor productivity into technological change and returns to scale. Technical change is reflected through the shift in the cost function where returns to scale is represented by the cost/output elasticity. This was achieved by linking the productivity growth to key parameters of a specific cost function. The study used cost of production data over the period 1961-2016 and specified a stochastic generalized translog cost function. Parameters were estimated using Seemingly Unrelated Regression (SUR) method. Estimation of the share of factor inputs in the total cost revealed that coconut cultivation is characterized by high labour share (61-67 \%) and low material share (24-27 \%) followed by low capital share (9-12\%). According to the results, the total factor productivity (TFP) was found to have grown at $0.083 \%$ per annum. Decomposing TFP, we found that technological change and scale of economies contributed to $78 \%$ and $22 \%$ of the TFP growth, respectively. The contribution of technical progress was greater towards the end of the considered time period while diseconomies of scale was operating throughout the period. Based on this, we recommend that the focus of the coconut sector development should be on technological interventions rather than the consolidation of coconut land.

*Corresponding author: abeysekaradilini@gmail.com 


\section{INTRODUCTION}

The long-run sustainable growth and development of an economy depends on the volume of output produced in the economy. The volume of output produced in the economy including agriculture, industry and the service sectors can be augmented by (i) increasing the factor inputs and (ii) efficient utilization of inputs in production. However, the land resources, one of the most important factor inputs for cultivation, is often scarce and the share of arable land is decreasing at an alarming rate due to factors operating from the environmental to the economic front. Hence, the agricultural sector has to rely on the efficient utilization of inputs in production. Therefore, productivity increase is the way out for improving the output of the agricultural sector. However, studies on selected crops and agricultural sector as a whole that explored the causes for the stagnation of the sector have invariably concluded that the agricultural scenario has been characterised by long-run incapability to deliver to the needs of the domestic economy (Kottayi, 2008).

Coconut, one of the three traditional plantation and export crops of Sri Lanka, has been confronted with stagnation in production over the past few decades. There have been some cyclical variations, with corresponding changes in prices from time to time. However, by and large, these changes have been caused by adverse weather rather than by an appreciable change in productivity. Coconut plays an important role in sustaining the national economy and food security of the people. It contributes about $0.7 \%$ to the Gross Domestic Products (GDP), $12 \%$ to the export earnings from agriculture, and $3.3 \%$ to the total export earnings (Central Bank of Sri Lanka, 2018). At present, in terms of the extent under cultivation, coconut is the most important tree crop in Sri Lanka and the sector accounts for $20 \%$ of the total arable lands, 443,536 ha, in the country. Coconut industry comprises of two distinct producer groups based on the size of land holdings namely estate sector (i.e. $>8$ ha) and the smallholder sector (i.e. $<8$ ha). Unlike the other plantation industries, coconut is closely integrated with the peasantry and economic and social life of a substantial section of the population.

\section{Problem statement}

Both institutional and technological factors provide backing for thriving the agricultural sector. Over the years, several institutional and technological factors have been identified and measures have been implemented in the coconut sector to improve the output generated. Land reform measures are one of the important institutional changes that invigorate agricultural development and this was initiated in the coconut sector in the early 1970 s by the direct intervention of the government by redistributing land among smallholders. The other institutional mechanisms implemented by the government include the provision of financial support in terms of credit, input subsidies, export duty and tariff on imported substitutes. The technical changes involved in the coconut sector ranges from the use of high yielding cultivars to technological advancements in irrigation, fertilizer and machines. Amidst all these efforts, slow growth and low returns of the coconut industry have been at the forefront of debate and controversy for over the decades. Many research studies in the recent past on the agriculture sector as a whole (Kalirajan et al., 1996; Saikia, 2009; Pattnaik and Shah, 2015) and on specific crops (Fogaras, 2006; Kottayi, 2008; Liu and Li, 2010; Aragon et al., 2013; Sawaneh et al., 2013), in particular, concluded that the prime factor behind the sluggishness of agricultural sector was the absence of productivity growth and stagnant technology in the sector.

Several studies have been conducted to assess the productivity growth in Sri Lanka and some of these studies include Fernandez et al. (2005), Duma (2007), Gamage and Kankanamge (2013) and Kumari and Tang (2019) where the focus was on the entire economy. Some of the sector-specific studies include; on building construction sector by Navaratne and Jayawardane (2007) and on food manufacturing industry by Swarnathilake et al. (2019). However, studies that focus exclusively on the productivity performance of agriculture in Sri Lanka are relatively few. In the context of coconut, there are no studies that exclusively focus on the productivity performance of the coconut sector as such and no attempt was there to compute the Total Factor Productivity (TFP) of the sector and to identify the sources of productivity growth. It is in this backdrop the present study was framed.

\section{Objectives of the study}

Technological change in agriculture is reflected directly on the productivity of crops and it enhances the productivity of land and improves the capability of agricultural labour. Therefore, a study of productivity in a particular crop is also a study of the technological change in the crop sector. Therefore, the objective of this study was to estimate the TFP growth and to identify the sources of productivity growth of the coconut sector by decomposing the measured growth in TFP into technological change and returns to scale. 


\section{METHODOLOGY}

For decades, different approaches have been developed to measure and identify sources of productivity change. The early examples of constructing superlative productivity indices using price and quantity data are provided by Fisher (1922) and Tornquist (1936) and it is then followed by Malmquist (1953) by developing an index to measure productivity change (Sharma et al., 2007). Solow (1957), introduced a procedure to measure productivity, often denoted as "growth accounting" and it has been later replicated for many other countries, time periods, and sets of inputs (Barro and Sala-I-Martin, 1995). However, these deterministic (non-parametric) approaches have tended to compute productivity as a residual after accounting for input growth and to interpret the growth in productivity as the contribution of technical progress (Rae et al., 2005). Nevertheless, these models do not consider random deviations and hence attribute all of the discrepancies from the frontier to inefficiencies of production although this would not be appropriate in cases where random measurement errors are present (Grosskopf, 1993; Sharma et al., 2007). In contrast, stochastic frontier models can account for the sources of TFP growth while allowing for a stochastic environment. Therefore, the stochastic (parametric) approach has been the subject of considerable recent research concerning both extensions and applications (Schmidt and Sickles, 1984; Battese and Coelli, 1995; Kumbhakar et al., 1999; Kumbhakar and Lovell, 2000; Kumbhakar, 2000). The econometric studies of productivity change used either a primal approach or a dual approach. The primal approach is based on direct estimation of a production function where the dual approach is based on the estimation of cost function or profit function. Most efforts to improve the theoretical framework of TFP measurement and attribution, using the parametric approach, have been based on duality and particularly, on cost function (Karagiannis and Mergos, 2000) and the cost function is more desired for econometric analysis over the production function for a variety of reasons (Brinswanger, 1974).

This study estimates the TFP change using cost function approach and decomposes the TFP change into two components namely technical change and the returns to scale. Technical change is reflected through the shift in the cost function where returns to scale is represented by the cost/output elasticity. Productivity growth is linked to key parameters relating to the cost/output elasticities of a specific cost function. Therefore, when the cost elasticities are identified, the inter-temporal shifts in the cost function and scale effects can be separated.

\section{Theoretical framework: Decomposition of TFP through Cost Function}

The decomposition exercise via cost function has been successfully done by Denny et al. (1981) for the Canadian regulated industrial sectors (i.e. electric utility industry and telecommunication sector) and it has been applied to South Korean manufacturing industries by Kwon (1986), the agricultural sector in Kerala by Kottayi (2008), in which the decomposition is linked to the cost function by cost/output elasticity. In the present study, the methodology followed by Kwon (1986) with modifications was applied to the Sri Lankan coconut sector.

The growth rate of TFP is defined as

$T \dot{F} P=\dot{Q}-\dot{F}$

(Equation 1)

Where $\dot{Q}$ is the rate of change of output, $\dot{\mathrm{F}}$ is the rate of change of total factor input; it is the proportionate change in the variables over time. For measuring $\dot{F}$, Divisia index (Star and Hall, 1976) is used.

$\dot{\mathrm{F}}=\sum \frac{P_{i} X_{i}}{C} \dot{\mathrm{X}}_{i}$

(Equation 2)

Where $\mathrm{Pi}$ is the price of input $\mathrm{i}, \mathrm{X}_{\mathrm{i}}$ the quantity of input $i, \dot{X}_{i}$ is the proportionate rate of growth of input $i$, and $C=\sum_{i} P_{i} X_{i}$, the total cost.

Under the assumption of cost-minimising behaviour, the duality theory implies that, for any production function, there exists a cost function that provides an equivalent description of the technology. The cost function with three explanatory variables can be represented as follows.

$$
C=f\left(P_{i}, Q, T\right)
$$

(Equation 3)

Where $\mathrm{P}$ is the input price vector, $\mathrm{Q}$ is the output, and $\mathrm{T}$ the index of technology, which is a simple time function. Differentiating the above (3) totally with respect to $\mathrm{T}$ and setting $\partial \mathrm{f} / \partial \mathrm{P}_{\mathrm{i}}=\mathrm{X}_{\mathrm{i}}$ by Shepherd's lemma, equation (4) could be expressed as:

$$
\dot{C}=\sum_{i} \frac{P_{i} X_{i}}{C} P^{\cdot}+\eta_{C Q} \dot{Q}+\dot{\theta} \quad \text { (Equation 4) }
$$

From which it follows that,

$\dot{\theta}=\dot{C}-\sum_{i} \frac{P_{i} X_{i}}{C} \dot{P}-\eta_{C Q} \dot{Q}$ (Equation 5) 
Equation (5) shows that the proportionate shift in the cost function $\dot{\theta}$ equals the proportionate change in costs $\dot{C}$ minus the proportionate change in aggregate inputs $\sum_{i} \frac{P_{i} X_{i}}{C} \dot{P}$ and the scale economies $\eta_{C Q} \dot{Q}$. An appropriate expression for $\sum_{i} \frac{P_{i} X_{i}}{C} \dot{P}$ is obtained by totally differentiating $C=$ $\sum_{i} P_{i} X_{i}$ with respect to time.

So that,

$\sum_{i} \frac{P_{i} X_{i}}{C} \dot{P}=\dot{C}-\sum_{i} \frac{P_{i} X_{i}}{C} \dot{X}$

(Equation 6)

Substituting (6) in (5), we obtain;

$-\dot{\theta}=\eta_{C Q} \dot{\theta}-\dot{F}$

(Equation 7)

$-\dot{F}=-\dot{\theta}-\eta_{C Q} \dot{Q}$

(Equation 8)

On substituting (8) in (1)

$$
T F \dot{P}=-\dot{\theta}+\left(1-\eta_{C Q}\right) \dot{Q}
$$

(Equation 9)

This study specifies a stochastic generalized translog cost function due to its flexibility as it imposes a relatively few a priori restrictions on the properties of the underlying technology. Further, it does not assume Hicks neutral or a constant rate of technological change. Elasticity of substitution between inputs is also allowed to vary with the level of inputs (Heathfield and Wibe, 1987). Productivity growth can be linked to key parameters relating to the cost/output elasticities of the specified cost function. The Translog specification of this generalised cost function as given in (3) is:

$\log C\left(Q, P_{i}, T\right)=\propto_{0}+\propto_{Q} \ln Q+$

$\sum_{i} \propto_{i} \ln P_{i}+\delta_{t} \ln T+\sum_{i} \beta_{Q i} \ln Q \ln P_{i}+$

$\sum_{i} \gamma_{i} \ln P_{i} \ln T+0.5 \sum_{i} \sum_{j} \beta_{i j} \ln P_{i} \ln P_{j}+$

$\gamma_{Q T} \ln Q \ln T+0.5 \alpha_{Q Q}(\ln Q)^{2}+$

$0.5 \delta_{T T}(\ln T)^{2}$

(Equation 10)

where $\mathrm{i}, \mathrm{j}=$ Labour (L), Capital (K), and Materials (M), $C$ and $Q$ are cost and output per acre, $P_{i}$, input prices and $\mathrm{T}$, the time variable. When there is $n$ number of explanatory variables, there will be $1+n$ $(n+1)$ / 2 parameter (when the symmetric condition is imposed) to be estimated in a translog function.

The cost share equations can be obtained from ( 7 , 8, 9 and 10) using Shepherd's lemma as;
$S_{i}=\propto_{i}+0.5 \sum_{j} \beta_{i j} \ln P_{i}+\beta_{Q i} \ln Q+\gamma_{i} \ln T$

(Equation 11)

for $i, j=$ Labour (L), Capital (K), and Materials (M) and $S i=\partial \ln C / \partial \ln P_{i}=P_{i} X_{i} / C$ is the cost share. There will be as many cost share equations as the number of inputs in the model. It follows that $\sum_{i} S_{i}=1$.

The cost/output elasticity estimates are obtained from the parametric estimates of the model, derived from (10).

$\eta_{C Q}=\propto_{Q}+\propto_{Q Q} \ln Q+\sum_{i} \beta_{Q i} \ln P_{i}+\gamma_{Q} \ln T$

(Equation 12)

\section{Data}

Cost of cultivation data for the entire coconut sector was not available. However, an annual time series of cost of cultivation of 1000 fresh coconut nuts from 1961/1962 to 2016/2017 were available in the Statistical abstracts published by the Department of Census and Statistics and these data were obtained for the analysis. The total cost of cultivation is composed of cost on hired human labour, machine labour, cost of fixed and working capital, repair and maintenance charges, manures, fertilizers and chemicals, plant protection charges, and other expenses. The total cost of production of coconut is divided into three components: labour cost, material cost, and the costs other than labour and material which are labelled as 'capital' cost. The observed cost share of each input is obtained on dividing the real input costs by real total cost.

The sum of expenses incurred on hired labour and machine labour is the total labour cost. The wages of agricultural labourers are available for the considered period of time. The nominal labour cost is deflated using the agricultural price index constructed for the purpose to get the real labour cost. Among the material cost; expenses on seed and seedlings, fertilizers, chemicals and farmyard manure, plant protection expenses, and other expenses are included. Price of every input is not available. However, the market prices of fertilizer are available and the market price of fertilizer is taken as a proxy for calculating the price of 'materials'. The material cost is deflated using the price index to get the real material cost. The expenditure of capital is available. This amount when deflated by the price index, the real capital is obtained.

\section{RESULTS AND DISCUSSION}

The parameters of the translog cost function were estimated through the joint estimation of equations (10) and (11) using Seemingly Unrelated 
Regression (SUR) method. STATA 13 statistical software was used for the analysis. Since the costshare parameters are a subset of the cost function parameters, exploiting the duality theory and estimating the cost-share equations jointly with the cost function was expected to increase the statistical degrees of freedom. From the jointly estimated parameters of the estimated Translog cost function, the cost/output elasticity was computed. The mean value of cost/output elasticity was obtained from the statistically significant estimates of cost/output elasticity and it was computed for each year on condition that the parameters of the equation were stable over the years. The input index was computed using the Tornqvist Index, which was the discrete approximation of the Divisia index*. The mean values were substituted in equation (7) from which an estimate of the technical change measured through the cost shift was obtained. The estimates of technical change and variable returns to scale put in equation (9) provided an estimate of the TFP. The growth rate of real cost per acre, the output per acre and the inputs were also estimated.

The estimates of the cost/output elasticity were found to be negative and statistically significant in many cases which is not a theoretically valid case. The cost/output elasticity being the ratio of marginal cost to average cost a negative estimate of it implied that marginal cost is negative which is not possible in the face of the total cost being monotonically increasing. In such circumstances, the cost/output elasticity was treated as zero. The cost/output elasticity can become zero when the marginal cost is zero, which occurs if the total cost (measured in real terms) remains constant at any level of output. This is possible when the farmers try to keep their cultivation expenses at a fixed level. As the cost of cultivation is kept at a predetermined level, the output increase is not reflected in its cost. The cost is not responding to output change resulting in the marginal cost being zero and thereby cost/output elasticity becomes zero. It may indicate a situation wherein cultivators, among other constraints, try to increase output with a cost constraint (Kottayi, 2008).

Table 1 presents the estimates of the translog cost function using the SUR approach. Accordingly, many of the coefficients in the cost function were not individually statistically significant. However, it is noted that most of the estimates used for calculating cost output elasticities were significant at $5 \%$ and $10 \%$ significant levels.

Table 1: Parameters estimates of the Seemingly Unrelated Regression Model

\begin{tabular}{lcr}
\hline Variable & Parameter & Estimates ( $\boldsymbol{p}$ value) \\
\hline Intercept & $\alpha_{0}$ & $24.1375^{*}(0.085)$ \\
Price of labour & $\alpha_{L}$ & $1.5473^{* *}(0.046)$ \\
Price of material & $\alpha_{M}$ & $1.6720^{*}(0.083)$ \\
Price of capital & $\alpha_{K}$ & $-0.7583(0.219)$ \\
Output (nut production) & $\alpha_{Q}$ & $-10.9978(0.859)$ \\
Time & $\delta_{T}$ & $1.3936^{*}(0.067)$ \\
plQ & $\beta_{Q L}$ & $0.1934^{*}(0.097)$ \\
pmQ & $\beta_{Q M}$ & $1.7238(0.358)$ \\
pkQ & $\beta_{Q K}$ & $0.1531(0.190)$ \\
tQ & $\beta_{Q T}$ & $0.6026^{* *}(0.031)$ \\
yy2 & $\alpha_{Q Q}$ & $-1.2212^{*}(0.092)$ \\
R-squared & & 0.8161 \\
\hline
\end{tabular}

Note: $\mathrm{pl}=$ price of labor, $\mathrm{pf}=$ price of material, $\mathrm{pk}=$ price of capital, $\mathrm{t}=$ time trend, $\mathrm{y}=$ output. All the other interactions terms were included in the model and only the parameter estimates used to calculate cost/output elasticity are presented. $^{* *}$ and $*$ denotes significance at $5 \%$ and $10 \%$ significance levels respectively.

\footnotetext{
* The Tornqvist index is the discrete approximation of the Divisia index number. The Tornqvist input index is given by $F=0.5\left(S_{i t}+S i t-1\right) \sum\left[\ln X_{j t}-\ln X_{j t-1}\right]$, where $S_{j t}$ is the share of $\mathrm{j}^{\text {th }}$ input in period $\mathrm{t}$ and $X_{j t}$ is the quantity of $\mathrm{j}^{\text {th }}$ input in period $\mathrm{t}$.
} 
Table 2: Share of factor inputs in the total cost

\begin{tabular}{cccc}
\hline Period & Labour & Capital & Materials \\
\hline 1961-62 to $1981-82$ & 0.6084 & 0.1163 & 0.2751 \\
1982-83 to $2002-03$ & 0.6530 & 0.0969 & 0.2500 \\
2003-04 to 2016-17 & 0.6710 & 0.0884 & 0.2405 \\
1961-62 to 2016-17 & 0.6385 & 0.1022 & 0.2593 \\
\hline
\end{tabular}

Table 2 presents the share of factor inputs in the total cost. As revealed by Table 2, the coconut cultivation was characterized by high labour share and low material share followed by low capital share. The share of labour remained more than 60 percent of the total input requirement for the cultivation of coconut. The share of material remained more than 25 percent while the use of capital remained around 10 percent. Further, it could be observed that the average contribution of each factor input in the total cost exhibited a marginal increase in labour share while the other two components showed a marginal decrease.

\section{Cost/Output elasticities}

The cost-output elasticity estimates are presented in Table 3. In order to reflect the changing phase of the coconut sector, the period under study was divided into three sub-periods: 1961-62 to 198182, 1982-83 to 2002-03 and 2003-04 to 2016-17; the first was the period where plantation sector was predominant while the latter periods were accompanying with land reformation and trade liberalization. The rate of returns to scale defined as $1-\eta_{\mathrm{cQ}}$ was 0.593 for the entire period, suggesting that the underlying technology exhibited substantial increasing returns to scale in the coconut sector. For the same period $\eta_{\text {CQ }}$ of 0.407 means that, on average, a $1 \%$ increase in output resulted in a $0.407 \%$ increase in the total cost. The gradual increasing of (1- $\left.\eta_{\mathrm{cQ}}\right)$ from one period to another period also suggested that the coconut sector has not been able to exploit the scale of economies through the expansion of the size of its operation.

\section{The contribution of changes in scale economies and technology to total factor productivity growth}

In order to characterize the growth of Sri Lankan coconut sector over the 1961-62 to 2016-17 period, the rates of growth of real inputs $(\dot{F})$, real outputs $(\dot{Q})$, were calculated for the three sub periods (Figure 1). As mentioned earlier, the Tornqvist index, the discrete approximation of the Divisia index was used to calculate the growth of total factor inputs $(\dot{F})$.

As shown in Figure 1, the annual average growth rate of coconut lagged behind the growth rate of the total cost of cultivation except during 1982-83 to 2002-03. This indicates the presence of the economic inefficiency in the coconut cultivation. The growth rate of total factor inputs shows negative growth in the latter two consecutive periods implying a reduction in the application of inputs. Similarly, growth rates of labour and capital registered negative growth during the same period indicating a failure in absorbing inputs. In contrast, the average annual growth rate of the material showed a positive growth when the entire period was considered.

TPF change estimated using the cost function approach was decomposed into two components; one part due to technical change reflected through the shift of cost function and the other returns to scale represented by cost/output elasticity. Table 4 presents the results of the decomposition exercise of TFP estimation.

Table 3: Estimates of cost/output elasticities and return to scale

\begin{tabular}{|c|c|c|}
\hline Period & Cost/output elasticity ( $\left.\eta c_{Q}\right)$ & Returns to scale (1- クcQ) \\
\hline $1961-62$ to $1981-82$ & 0.000 & 0.000 \\
\hline $1982-83$ to $2002-03$ & 0.647 & 0.353 \\
\hline $2003-04$ to $2016-17$ & 0.239 & 0.761 \\
\hline $1961-62$ to $2016-17$ & 0.407 & 0.593 \\
\hline
\end{tabular}




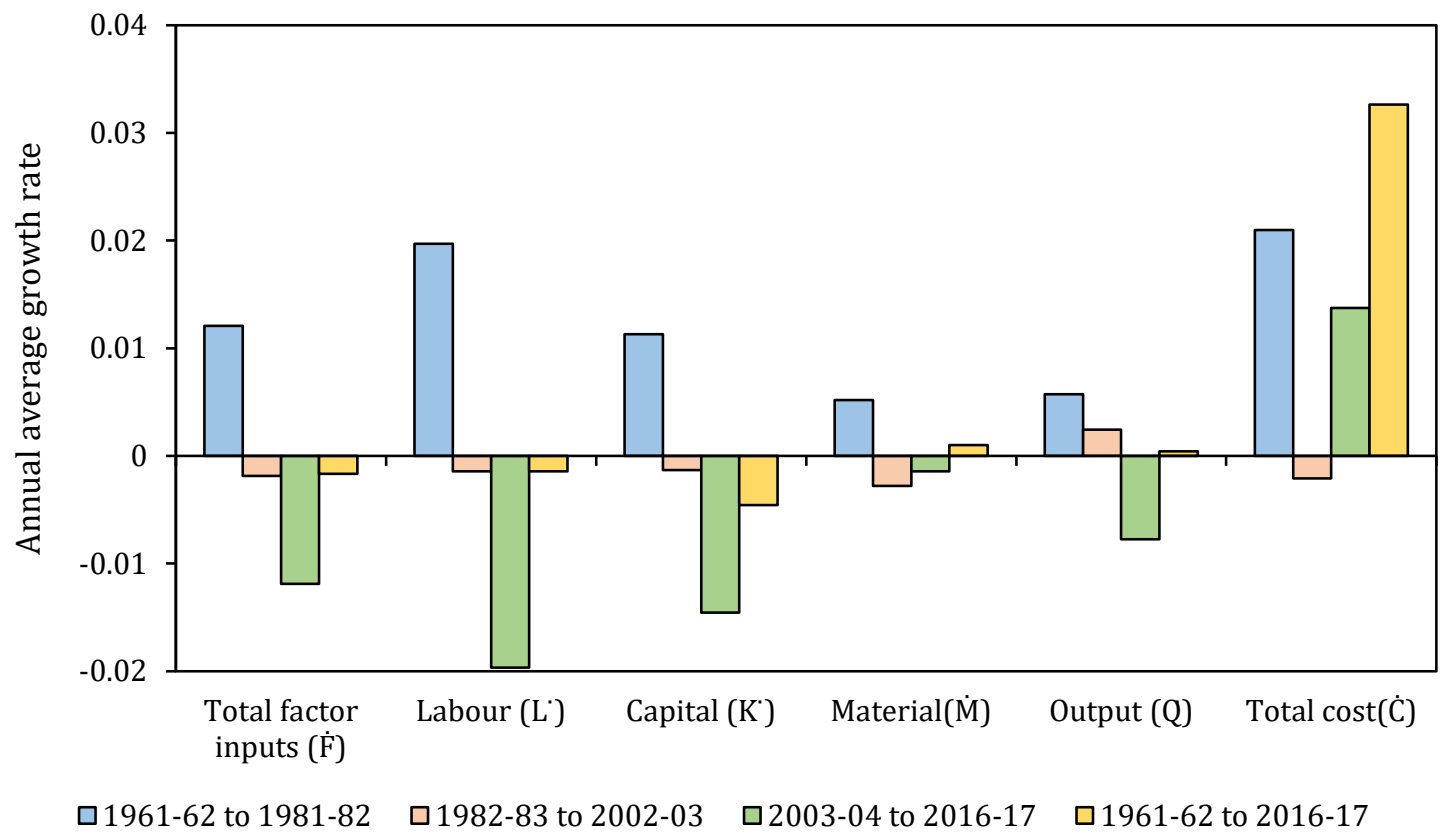

Figure 1: Average annual growth rates of real inputs, output and total cost

The rates of growth of TFP were $0.123 \%$ for the $1961-62$ to $1981-1982$ period, $0.078 \%$ for the next period followed by $0.1 \%$ in the last period. The rate of growth of TPF for the entire period was $0.083 \%$. This estimate was consistent with the rate of growth of TFP recorded for coconut in Kerala, $0.051 \%$, a study conducted for the period 1980-81 to 2004-05 (Kottayi, 2008), for coconut in the Philippines,1.52\% (Aragon et al., 2013), other perennials like tapioca, $0.017 \%$ (Kottayi, 2008) and annual crops such as soybean, $0.42 \%$ (Liu and Li, 2010), and rice,1.014\% (Sawaneh et al., 2013).

The technical change represented by the proportionate shift in the cost function has become increasingly important over time in the development of the Sri Lankan coconut sector. It accounted for $95 \%$ of the rate of growth during the most recent period and $78 \%$ in the entire period. The implications of the numerical findings were evident in the real context. During the past few decades, the primary focus of the coconut sector development was directed towards technological advancements. Introduction of high yielding varieties and efficient land-use practices, and sustainable management of soil fertility have been carried out to increase productivity. Despite the land

Table 4: Decomposition of Total Factor Productivity into Technical Change and Returns to Scale and percentage contribution

\begin{tabular}{|c|c|c|c|c|c|c|}
\hline \multirow{2}{*}{$\begin{array}{l}\text { Period } \\
2 \text { to } 1981-82\end{array}$} & \multicolumn{2}{|c|}{$\begin{array}{c}\text { Total Factor } \\
\text { Productivity } \\
T \dot{F P} \\
\end{array}$} & \multicolumn{2}{|c|}{$\begin{array}{l}\text { Shift of cost function } \\
\qquad-\dot{\theta}\end{array}$} & \multicolumn{2}{|c|}{$\begin{array}{l}\text { Non-constant Returns } \\
\text { to scale }\left(1-\eta_{C Q}\right) \dot{Q}\end{array}$} \\
\hline & & 0.123 & & $\begin{array}{r}0.045 \\
(36.59 \%)\end{array}$ & & $\begin{array}{r}0.078 \\
(63.41 \%)\end{array}$ \\
\hline $1982-83$ to $2002-03$ & 0.083 & 0.078 & $\begin{array}{r}0.065 \\
(78.31 \%)\end{array}$ & $\begin{array}{r}0.027 \\
(34.62 \%)\end{array}$ & $\begin{array}{r}0.018 \\
(21.69 \%)\end{array}$ & $\begin{array}{r}0.051 \\
(65.38 \%)\end{array}$ \\
\hline $2003-04$ to $2016-17$ & & 0.100 & & $\begin{array}{r}0.095 \\
(95.00 \%)\end{array}$ & & $\begin{array}{r}0.005 \\
(5.00 \%)\end{array}$ \\
\hline
\end{tabular}


fragmentation and gradual increment of smallholders, the national yield has increased from 6,413 to 7,109 nuts/ha/year owing to these technological improvements. Introduction of Coconut Based Agroforestry Systems (CBAS) and intercropping systems were the other developed areas which may have subsequently improved the productivity of the coconut monoculture. However, technological progress associated with the reduction of cost of cultivation was best reflected through a downward shift in the cost function. In contrast, there was an upward shift in the resulted cost function indicating that the underlying technological change has not resulted in a reduction of cost of cultivation. Even though most of the technological improvements were centred on yield improvement, the introduction of laboursaving mechanisms was minimal in the sector. Scarcity of labour in major coconut growing areas has substantially increased the price of labour, thus resulting in an increase in the total cost of cultivation.

In contrast to the technological change, the scale of economies has become less important over time declining from $63 \%$ to $5 \%$ during the considered period of time (Table 4). Returns to scale parameter indicated the proportionate increase in output for a proportionate increase in all inputs. Therefore, the declining trend of returns to scale was due to the increased use of inefficient inputs and reduction of productivity of individual factors.

For the comparison purpose of the estimates, the decomposition estimates with a similar study are presented in Figure 2. According to Figure 2, the technological change represented by a shift of cost function contributes significantly to the TPF growth in Sri Lankan coconut sector whereas the scale of economies plays a significant role in the TFP growth in the Kerala coconut cultivation. These results can be attributed to the difference in size class distribution in the two countries. Similar pattern could be observed in areca and rice in the Indian context.

\section{CONCLUSIONS}

Given the stagnating nature of the production and declining the area under cultivation, this study attempts to identify the sources of productivity growth of the coconut sector over time by decomposing the measured growth in total factor productivity into technology, returns to scale. Such an analysis can examine whether the introduction of competition, the privatization of state enterprises, the removal of trade barriers, and the introduction of regulation or deregulation have resulted in efficiency improvements or, indeed, whether the evidence

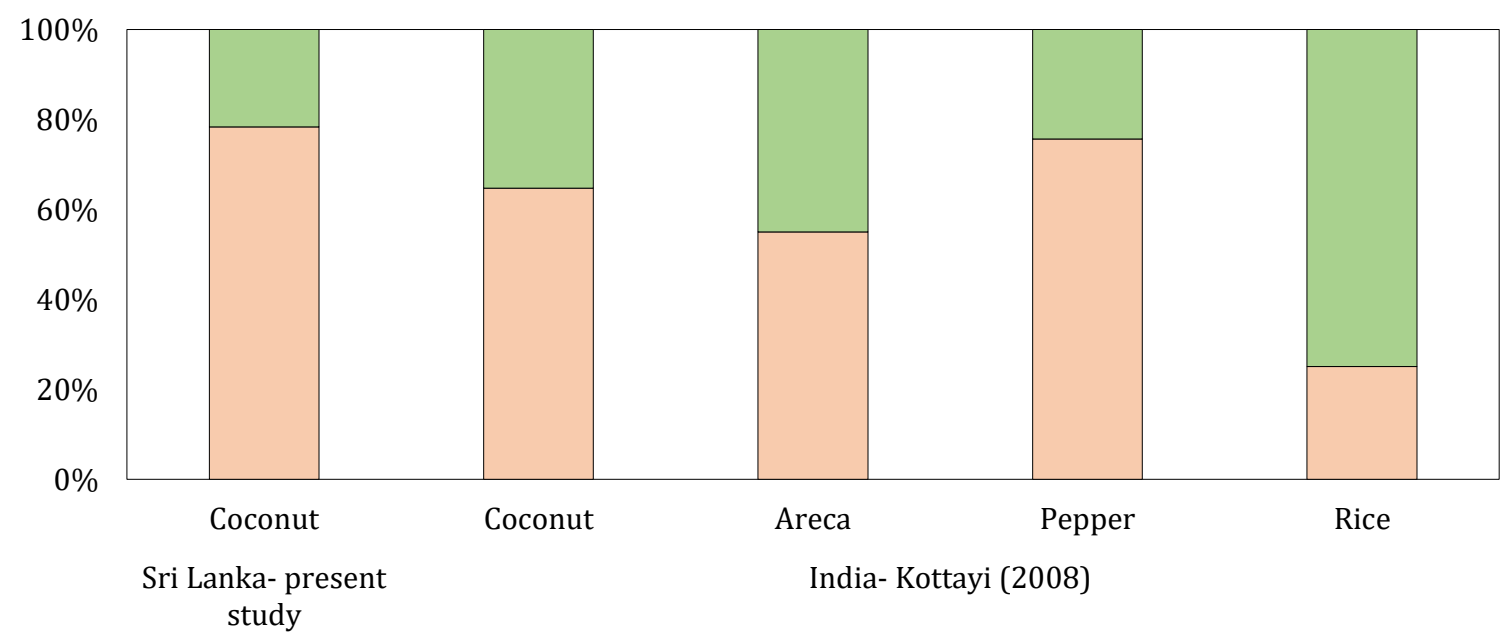

$\square$ Shift of cost function $\quad \square$ Non constant returns to scale

\section{Figure 2: Comparison of decomposition of TPF growth with previous studies}

Note: 1. Present study- Annual national data 1962-2017

2. Kottayi (2008) - Annual state level data for Kerala from 1980 to 2005 
suggests that changes are likely to lead to future efficiency improvement. The study used estate sector data from 1961-62 to 2016-17 and the study used the cost function approach to estimate and decompose the TPF. The results revealed that the rate of returns to scale is 0.593 for the entire period, suggesting that the underlying technology exhibited substantial increasing returns to scale in the coconut sector. TFP was found to have grown at $0.083 \%$ per annum and the technological progress i.e. Introduction of high yielding varieties, comprised of the majority of TFP growth contributing $78 \%$ of the growth of TFP while scale economies contributed 22\%. The gradual increasing of returns to scale $\left(1-\eta_{C O}\right)$ from one period to another period also suggested that the coconut sector has not been able to exploit the scale of economies through the expansion of the

\section{REFERENCES}

Aragon, C.T., Carambas, N., Andres, R.T., Roxas, K.G. and Fernandez, D.P. (2013). Total Factor Productivity Growth in the Philippine Coconut and Sugarcane Sub-sectors. In Productivity growth in Philippine Agriculture (pp. 1-48). Philippines: SEARCA, DA-BAR, and PhilRice.

Barro, R.C. and Sala-I-Martin. (1995). Economic growth. New York: McGraw-Hill.

Battese, G.E. and Coelli, T.J. (1995). A Model for Technical Inefficiency Effects in a Stochastic Frontier Production Function for Panel Data. Empirical Economics. 20, 325-332.

Brinswanger, H.P. (1974). A Cost Function Approach to the Measurement of Elasticities of Factor Demand and Elasticities of Substitution. American Journal of Agricultural Economics. 56(2), 377-386

Central Bank of Sri Lanka (2018). Annual Report. Colombo: CBSL.

Das, P.K. (1986). Movement of Wholesale Prices of Coconut, Copra and Coconut oil in Kerala during the Last Two and Half Decades. Journal of Plantation Crops. 14(2), 105-114.

Denny, M., Fuss, D. and Waverman, L. (1981). on of Total Factor Productivity in Regulated Sector: The Electric Utility Industry. In T. Cowing, and R. Stevenson (Eds.), The measurement and interpretation of Total Factor Productivity in size of its operation. The technical change represented by the proportionate shift in the cost function has become increasingly important over time in the development of the Sri Lankan coconut sector while the scale of economies has become less important over time. Based on this, we recommend that the focus of the coconut sector development should be on technological interventions rather than the consolidation of coconut land.

\section{ACKNOWLEDGEMENTS}

Authors appreciate the assistance received in data compilation. This data series published in the Statistical abstract has been compiled by P.M.E.K. Pathiraja from 1960 to 2008 and the rest was compiled by the authors.

the regulated industries (pp. 179-218). New York: Academic Press.

Department of Census and Statistics. (2014). Economic Census 2013/2014- Agricultural Activities. Colombo: Department of Census and Statistics.

Duma, N. (2007). Sri Lanka's Sources of Growth. Washington D.C.: International Monetary Fund.

Fernandez, E., Lueth, E., Davies, M. and Kock, U. (2005). Sri Lanka: Selected Issues and Statistical Appendix. Washington D.C.: International Monetary Fund.

Fogaras, J. (2006). Efficiency and total factor productivity in post-EU accession Hungarian sugar beet production. Studies in Agricultural Economics. 105, 87-100.

Gamage, G.G. and Kankanamge, A. (2013). Factors Affecting Total Factor Productivity Growth in Sri Lanka. Modern Sri Lanka Studies. 4(1), 1-24.

Grosskopf. (1993). Efficiency and Productivity. In H.O. Fried, C.K. Lovell, and S.S. Schmidt (Eds.), The Measurement of Productive Efficiency: Techniques and Applications. New York: Oxford University Press.

Heathfield, D.F. and Wibe, S. (1987). The Translog Function. In: An Introduction to Cost and Production Functions. London: Palgrave. doi:doi.org/10.1007/978-1-349-18721-8_

Kalirajan, K.P., Obwona, M.B. and Zhao, S. (1996). A Decomposition of Total Factor Productivity 
Growth: The Case of Chinese Agricultural Growth before and after Reforms. American Journal of Agricultural Economics. 78(2), 331338. Retrieved 6 10, 2020, from URL: https://www.jstor.org/stable/1243706

Karagiannis, G. and Mergos, G.J. (2000). Total Factor Productivity Growth and Technical Change in a Profit Function Framework. Journal of Productivity Analysis. 14, 31-51.

Kottayi, S.B. (2008). Productivity behaviour in Kerala's Agriculture. The University of Calicut, Department of Economics. Unpublished.

Kumari, R.D. and Tang, S.H. (2019). Sri Lanka's Sources of Growth: The Application of Primal and Dual Total Factor Productivity Growth Accounting Approaches. 12 $2^{\text {th }}$ International Research Conference. Colombo: Central Bank of Sri Lanka.

Kumbhakar, S.C. (2000). Estimation and Decomposition of Productivity Change When Production Is Not Efficient: A Panel Data Approach. Econometric Reviews. 19, 425-460.

Kumbhakar, S.C. and Lovell, A.K. (2000). Stochastic Frontier Analysis. Cambridge University Press.

Kumbhakar, S.C., Heshmati, A. and Hjamarsson, L. (1999). Parametric Approaches to Productivity Measurement: A Comparison Among Alternative Models. Scandinavian Journal of Econometrics. 101, 404-424.

Kwon, J.K. (1986). Capital Utilization, Economies of Scale and Technical Change in the Growth of Total Factor Productivity. Journal of Development Economics. 24, 75-89.

Liu, M. and Li, D. (2010). An Analysis on Total Factor Productivity and Influencing Factors of Soybean in China. Journal of Agricultural Science. 2(2), 158-163.

Navaratne, D. and Jayawardane, A. (2007). Total Factor Productivity in the Building Construction. Engineer. 40(1), 63-70.
Pattnaik, I. and Shah, A. (2015). Trends and Decomposition of Agricultural Growth and Crop Output in Gujarat: Recent Evidence. Indian Journal of Agricultural Economics. 70(2), 183196.

Rae, A.N., Ma, H., Huang, J. and Rozelle, S. (2005). Livestock in China: Commodity-specific Total Factor Productivity Decomposition Using New Panel Data. American Journal of Agricultural Economics, 88(3), 680-695.

Saikia, D. (2009). Total Factor Productivity in Indian Agriculture: Some Conceptual and Methodological Issues. MPRA Paper No. 28578. Retrieved from https://mpra.ub.unimuenchen.de/id/eprint/28578

Sawaneh, M., Latif, I. and Abdullah, A. (2013). Total Factor Productivity of Rice Farming in Selected South East Asian Countries. Proceeding of the International Conference on Social Science Research. Penang, Malaysia: WorldConferences.net.

Schmidt, P. and Sickles, R.C. (1984). Production Frontiers and Panel Data. Journal of Business and Economic Statistics. 2, 367-374.

Sepala, A.C. (1986). Socio-Economic Conditions of Coconut Small-Holding Sector in Sri Lanka. Colombo: Agrarian Research and Training Institute Sri Lanka.

Sharma, S.C., Sylwester, K. and Margono, H. (2007). Decomposition of Total Factor Productivity Growth in U.S. States. The Quarterly Review of Economics and Finance. 47, 215-241.

Solow, R.M. (1957). Technical Change and the Aggregate Production Function. Review of Economics and Statistics. 39, 312-320.

Swarnathilake, C., Weerahewa, J. and Bandara, Y.M. (2019). Productivity Growth in Food Manufacturing Industry: Empirical Evidence from Post reform Sri Lanka. Global Business Review. 1-25. https://doi.org/10.1177/09721 50919884405 